\title{
A DETERMINAÇÃO COLORIMÉTRICA DE VAPÔRES DE BENZENO NO AR (1)
}

\author{
Herbert M. A. STETTINER
}

\begin{abstract}
Stettiner, H. M. A. - A determinação colorimétrica de vapôres de benzeno no ar. Rev. Saúde públ., S. Paulo, 4:45-49, jun. 1970.

Resumo - Estudou-se um método simples para a determinação de pequenas quantidades de vapôres de benzeno no ar, aplicável em presença de seus homólogos. A interferência dos homólogos é eliminada destruindo seus nitrocompostos segundo BAERNSTEIN 1 (1943) pela oxidação com ácido crômico. Este procedimento é combinado com o de DoLIN 2, 3 (1943, 1947) que isola o m-dinitrobenzeno pela extração com éter etílico, usando o extrato etéreo para a revelação da côr vermelha e para a colorimetria.
\end{abstract}

O perigo que a inalação de vapôres de benzeno representa para a saúde requer um método simples e exato que permita determiná-los na atmosfera de fábricas. O método deve ser específico no sentido de excluir a interferência de vapôres de homólogos do benzeno, especialmente tolueno e xileno, que o acompanham freqüentemente.

O procedimento geralmente aceito é executado em dois passos. No primeiro o benzeno é transformado em m-dinitrobenzeno por meio de ácido de nitração. No segundo o produto da nitração é separado e, pela adição de 2-butanono (metiletilcetona), um composto vermelho é formado cuja concentração é medida por colorimetria. Com base em pesquisas de Reitzenstein \& Stamm ${ }^{6}$ (1910) atribui-se a fórmula

$$
\mathrm{Na}-\mathrm{NO}=\mathrm{C}_{6} \mathrm{H}_{4} \mathrm{NO}_{2}-\mathrm{OC}_{\text {I. }} \mathrm{C}_{2} \mathrm{H}_{5}
$$

à substância colorida. A coloração obedece à lei de BEER em relação à quantidade analisada de benzeno, porém, os homólogos do benzeno reagem anàlogamente e interferem nas medições colorimétricas. BAERNSTEIN ${ }^{1}$ (1943) propõe eliminar os efeitos produzidos pelos homólogos destruindo seus nitrocompostos pela oxidação com ácido crômico, logo após o primeiro passo da análise. Verificou que o m-dinitrobenzeno não é atacado. Dolin ${ }^{2,3}$ (1943, 1947), recomenda destruir com ácido acético os compostos coloridos produzidos pelos homólogos.

Observamos, em concordância com MUELler $^{5}$ (1955) e BaERNSTEIN ${ }^{1}$ (1943) que o ácido acético não se limita a

Recebido para publicação em 13-1-1970.

(1) Da Disciplina de Higiene do Trabalho do Departamento de Saúde Ambiental da Faculdade de Saúde Pública da USP — São Paulo, S.P., Brasil. 
STETTINER, H. M. A. - A determinação colorimétrica de vapôres de benzeno no ar. Rev. Saúde públ., S. Paulo, 4:45-49, jun. 1970.

reagir com os derivados dos homólogos. Ataca também os do próprio benzeno, afetando sensìvelmente a exatidão dos resultados da análise. Porisso resolvemos adotar o recurso de que se vale BAERNS. TEIN $^{1}$, qual seja o de eliminar os homólogos pelo ácido crômico, logo em seguida à nitração.

Para revelar o corante, o m-dinitrobenzeno deve ser separado do líquido de nitração, sendo extraído com um dissolvente orgânico. Para êsse fim BaERnstein ${ }^{1}$ emprega o próprio butanono. A solubilidade elevada desta cetona em água $(35,3$ g em $100 \mathrm{ml} \mathrm{a} 10^{\circ} \mathrm{C}$ ) e a necessidade de empregarmos quantidades relativamente grandes tornam o seu uso desaconselhável. MUELLER ${ }^{5}$ extrai com clorofórmio, mas o procedimento é complicado e custoso, envolvendo três extraçōes com evaporação do clorofórmio. DoLis ${ }^{2,3}$ recomenda extrair com éter etílico, e o extrato serve diretamente para revelar a côr, sendo necessário pouco butanono. Assim, pareceunos vantajoso combinar a eliminação dos homólogos pelo ácido crômico com a extração com o éter etílico.

\section{TODOS}

Captação e nitração - A captação dos vapôres de benzeno é feita pela própria nitração. Seguimos o método descrito por $J_{\text {ACOBS }}{ }^{4}$ (1949) usando o borbulhador especial elaborado para vapôres de benzeno por Yant, Pierce \& Schrenk ${ }^{8}$ (1936), ou um borbulhador comum com tampa esmerilhada de vidro e ponta capilar. Nas nossas experiências, os volumes de ar aspirado variaram entre $0,6 \mathrm{e}$ 1,51 , com vazões entre 25 e $50 \mathrm{ml} / \mathrm{min}$, e concentrações de benzeno entre 30 e 240 ppm aproximadamente.

Terminada a captação, desliga-se o borbulhador e juntam-se uma a três gôtas de solução saturada de trióxido de crômio em água. Aquece-se num banho de água a $75^{\circ} \mathrm{C}$ durante $10 \mathrm{~min}$; esfria-se e trans- fere-se o conteúdo do borbulhador (sem as esferas de vidro do tipo de YANT $^{\text {B }} \mathrm{e}$ colabs.) para um balão volumétrico de $100 \mathrm{ml}$, refrigerado com gêlo. Lava-se o borbulhador duas ou três vêzes com porções de $2 \mathrm{ml}$ de ácido de nitração e, a seguir, com água a $0^{\circ} \mathrm{C}$, juntando-se os líquidos da lavagem no balão volumétrico. Deixa-se o balão atingir a temperatura do ambiente e completa-se o conteúdo com água até a marca.

Separação do m-dinitrobenzeno Transferem-se volumes alíquotas convenientes (no máximo $20 \mathrm{ml}$ ) do balão volumétrico para funis de separação de $\mathbf{1 2 5}$ ml juntando água, se necessário, até o líquido no funil perfazer $20 \mathrm{ml}$. Extraise o dinitrobenzeno com $15 \mathrm{ml}$ de éter etílico "farm. bras." agitando vigorosamente. A camada aquosa é rejeitada e a etérea é lavada uma vez com $15 \mathrm{ml}$ de água para livrála de restos de ácido. Transfere-se a solução etérea para um balão volumétrico de $25 \mathrm{ml}$ com cuidado para que gôtas de água aderentes às paredes do funil não passem juntamente com o éter, pois a presença de água na solução final provoca turvações que impedem a medirão colorimétrica. Completa-se o volume no balão volumétrico com álcool absoluto redestilado sôbre cal virgem.

Revelação da côr e colorimetria Transferem-se $5 \mathrm{ml}$, exatamente medidos, da solução etéreo-alcoólica para o tubo ou para a célula do colorímetro. Juntamse exatamente $1 \mathrm{ml}$ de butanono, de pureza alta ${ }^{(1)}$, e $0,25 \mathrm{ml}$ de solução alcoó. lica de hidróxido de sódio a 4\%. Mistura-se bem, fecha-se o tubo e coloca-se imediatamente em banho de água conservado no escuro e mantido rigorosamente à temperatura de $18-18,5^{\circ} \mathrm{C}$. Decorridos exatamente 15 min, mede-se a transmitância com filtro de $550 \mathrm{~m} \mu$. Observamos que se pode fazer uso de água destilada para servir de padrão zero. Calcula-se

(1) Nas nossas determinacões usamos o produto n.o 383 da Eastman Kodak Co. 
STETTINER, H. M. A. - A determinação colorimétrica de vapôres de benzeno no ar. Rev. Saúde públ., S. Paulo, 4:45-49, jun. 1970.

a absorbância e determina-se a quantidade de benzeno pelo gráfico descrito abaixo. Os volumes dos líquidos empregados na revelação podem ser modificados proporcionalmente para obter $o$ volume final necessário ao funcionamento do colorímetro disponível.

Discussão de algumas modificações do procedimento - Para o repouso no escuro que precede a medição colorimétrica DoLIN recomenda 5 ou $10 \mathrm{~min}$ respectiva. mente nos seus dois trabalhos. Preferi. mos conservar a duração de $5 \mathrm{~min}$, tendo notado que o prolongamento do tempo pode resultar numa diminuição da absorbância. A temperatura constante e relativamente baixa mantida durante o repouso $\left(18\right.$ a $\left.18,5^{\circ} \mathrm{C}\right)$ diminui a sensibilidade contra a incidência ocasional de raios de luz e eventuais pequenas transgressões do tempo de repouso. Nas nossas primeiras experiências pudemos observar que, em temperaturas não controla. das, estas sensibilidades influem apreciàvelmente na reprodutibilidade dos resultados.

Para as nossas experiências dispusemos dum fotocolorímetro "Lumetron $401 \mathrm{~A}$ ". Entre os vários filtros de que é provido, escolhemos o de $550 \mathrm{~m} \mu$ por fornecer a absorbância maior, embora BAERNSTEIN ${ }^{1}$ tenha recomendado filtros entre 560 e $580 \mathrm{~m} \mu$.

Construção do gráfico com quantidades conhecidas de benzeno - Porçöes de benzeno, entre 30 e $75 \mathrm{mg}$, são pesadas em pequenas ampolas de vidro de parede muito fina. São obtidas fàcilmente soprando-as de tubos capilares. Dentro de um frasco de vidro fechado com rôlha esmerilhada que contém $5 \mathrm{ml}$ de ácido de nitração e um pedaço de vidro grosso, a ampola é quebrada e o seu conteúdo é exposto à ação do ácido. Prossegue-se como foi descrito acima para o tratamento do vapor de benzeno captado, tomando porém o cuidado de limitar o primeiro aquecimento do frasco a $60^{\circ} \mathrm{C}$ e soltando a rôlha, às vêzes, cuidadosamente, para diminuir a pressão.

O tamanho do balão volumétrico no qual o líquido de nitração é diluído não é necessàriamente de $100 \mathrm{ml}$. Deve ser escolhido de maneira a poder colocar volumes alíquotas nos funis de separação cujo teor em m-dinitrobenzeno permitirá a medição da transmitância após a trans. formação em matéria colorida.

Reunimos as absorbâncias que obtivemos na Tabela 1. Cada valor representa a média de três determinações separadas. Comparando as quantidades de benzeno colocado com as absorbâncias achadas em papel milimetrado obtém-se a linha reta que a lei de BeEr exige.

T A B E L A 1

Absorbâncias produzidas por quantidades de benzeno variadas entre 10 e $100 \mu \mathrm{g}$

\begin{tabular}{cc}
\hline $\begin{array}{c}\text { Benzeno colocado } \\
\mu g\end{array}$ & Absorbância achada \\
\hline 10 & 0,0265 \\
20 & 0,0549 \\
30 & 0,0822 \\
40 & 0,1146 \\
50 & 0,1410 \\
60 & 0,1710 \\
70 & 0,1960 \\
80 & 0,2267 \\
90 & 0,2553 \\
100 & 0,2773 \\
\hline
\end{tabular}

R E S U L T A D S

Aplicabilidade na presença de homólogos - 0 procedimento que acabamos de descrever para a construção do gráfico foi aplicado a porções de benzeno (entre $10 \mathrm{a} 90 \mu \mathrm{g})$, às quais se juntou tolueno ou xileno na base de $50 \%$ da quantidade colocada de benzeno. 
STETTINER, H. M. A. - A determinação colorimétrica de vapôres de benzeno no ar. Rev. Saúde públ., S. Paulo, 4:45-49, jun. 1970.

Conclui-se que, na presença de homó. logos, há um ligeiro aumento do benzeno recuperado em comparação com o colocado (Tabela 2).

T A B L A 2

Determinações de benzeno na presença de seus homólogos

\begin{tabular}{cc|cc}
\hline \multicolumn{2}{c|}{ Benzeno } & \multicolumn{2}{c}{$\begin{array}{c}\text { Erro } \\
\text { (Dif. entre Col. e } \\
\text { Recup.) }\end{array}$} \\
\hline $\begin{array}{c}\text { Colocado } \\
\mu \mathrm{g}\end{array}$ & $\begin{array}{c}\text { Recuperado } \\
\mu \mathrm{g}\end{array}$ & $\begin{array}{c}\text { Absoluto } \\
\mu \mathrm{g}\end{array}$ & $\begin{array}{c}\text { Relativo } \\
\%\end{array}$ \\
\hline 10,0 & 10,0 & 0,0 & 0,0 \\
30,0 & 31,8 & 1,8 & 6,0 \\
50,0 & 52.9 & 2,9 & 5,8 \\
70,0 & 74,3 & 4,3 & 6,1 \\
90,0 & 93,3 & 3,3 & 3,7 \\
\hline
\end{tabular}

T A B E L A 3

Determinações de vapor de benzeno no ar

\begin{tabular}{cc|cc}
\hline \multicolumn{1}{c|}{ Benzeno } & \multicolumn{2}{c}{$\begin{array}{c}\text { Erro } \\
\text { (Dif. entre Col. e } \\
\text { Recup. }\end{array}$} \\
\hline $\begin{array}{c}\text { Colocado } \\
\text { ppm }\end{array}$ & $\begin{array}{c}\text { Recuperado } \\
\text { ppm }\end{array}$ & $\begin{array}{c}\text { Absoluto } \\
\text { ppm }\end{array}$ & $\begin{array}{c}\text { Relativo } \\
\%\end{array}$ \\
\hline 29,5 & 28,8 & 0,7 & 2,4 \\
32,7 & 34,6 & 1,9 & 5,8 \\
54,0 & 54,6 & 0,6 & 1,1 \\
127,8 & 132,3 & 4,5 & 3,5 \\
128,8 & 128,1 & 0,7 & 0,5 \\
129,1 & 131,4 & 2,3 & 1,8 \\
131,1 & 130,3 & 0,8 & 0,6 \\
175,6 & 176,0 & 0,4 & 0,2 \\
241,4 & 246,8 & 5,4 & 2,2 \\
\hline 12 & & & \\
\hline
\end{tabular}

Ar contaminado com vapôres de benzeno - As concentrações de vapor de benzeno nas misturas analisadas variaram entre 29,5 e 241,4 ppm. Foram tratadas como é descrito ccima sob "Métodos". Preparamos as misturas num conjunto de 3 bombonas de vidro, de 251 cada, ligadas em série. Controlamos a constância das amostras fornecidas pelo dispositivo, analisando misturas de ar com determinadas quantidades de vapor de sulfêto de carbono. Para a determinação dêste último servimo-nos do método de VILES $^{7}$ (1940).

$\mathrm{Na}$ Tabela 3 reunimos os resultados ob. tidos com vapor de benzeno. Os números de ppm encontrados na coluna "Benzeno Recuperado" representam as médias aritméticas de três amostras retiradas em seguida, do mesmo carregamento das bom. bonas.

D I S C U S S $\AA$ O

Os diversos erros relativos apresentam uma média aritmética de $2 \%$. A comparação dos nossos resultados com os dos autores citados é dificultada pelo fato de serem escassos os dados numéricos por êles publicados. DoLis ${ }^{2,3}$ atingiu uma exatidão de $0,9 \%$; porém empregou grandes quantidades $(12,5 \mathrm{~g})$ de benzeno, enquanto que nosso procedimento foi aplicado a quantidades de microgramas. BaERnstein ${ }^{1}$, por outro lado, admite erros relativos até $5 \%$, de maneira que, em comparação com êle, conseguimos melhorar a determinação de benzeno no ar tanto na viabilidade como nos resultados.

StetTiner, H. M. A. - [The colorimetric determination of benzene vapors in air]. Rev. Saúde públ., S. Paulo, 4:45-49, jun. 1970

SUMmary - A simple method is developed for the determination of "small amounts of benzene vapor in air in the presence of its homologues. The chromic acid 
STETTINER, H. M. A. - A determinação colorimétrica de vapôres de benzeno no ar. Rev. Saúde públ., S. Paulo, 4:45-49, jun. 1970.

method of BAERNSTEIN 1 (1943) for eliminating the interference of the homologues is combined with the procedure of DoLIN 2,3 (1943, 1947) who makes the final colorimetric measurement after separating the colored matter by extraction with ethyl ether.

\section{REFERENCIAS BIBLIOGRĀFICAS}

1. BAERnStein, H. D. - Photometric determination of benzene, toluene and their nitroderivatives. Ind. Eng. Chem., Anal. Ed., 15:251-53, Apr. 1943.

2. DOLIN, B. H. - Determination of benzene. Ind. Eng. Chem., Anal. Ed., 15:242-47 , Apr. 1943.

3. DOLIN, B. H. - Benzene and its determination. Mon. Rev. Div. industr. Hyg. N.Y., 25, Apr. 1946.
4. JACOBS, M. B. - The analytical chemistry of industrial poisons, hazards and solvents. 2nd. ed. New York, Interscience Publishers Inc., 1949, p. 528.

5. MUELLER, P. A. - Nuevo metodo para determinacionešs de benzeno por espectrofotometria. Lima, 1955. [Tese para Bacharelado - Faculdade de Química da Universidad Mayor de San Marcos].

6. REITZENSTEIN, F. \& STAMM, G. Ueber die Janovskysche Reaktion der Dinitrokoerper und die von Bittosche Reaktion der Aldehyde und Ketone mit aromatischen Verbindungen. $J$. prakt. Chem., 81:167-76, Feb. 1910.

7. VILES, F. J. - Field determination of carbon disulfide in air. $J$. industr. Hyg. Toxicol., 22:188-96, May 1940.

8. YANT, W. P.; PEARCE, S. J. \& SCHRENK, H.H. - apud JACOBS, M. B. 4 p. 528. 